\title{
THE CHROMOSOMAL LOCATION OF GAI 1 AND RHT 1 , GENES FOR GIBBERELLIN INSENSITIVITY AND SEMI- DWARFISM, IN A DERIVATIVE OF NORIN 10 WHEAT
}

\author{
M. D. GALE and GERALDINE A. MARSHALL \\ Plant Breeding Institute, Cambridge
}

Received 5.ii.76

\begin{abstract}
SUMMARY
The gene conferring gibberellin insensitivity, Gai 1, was located on chromosome $4 \mathrm{~A}$. This gene is associated with the semi-dwarf habit and consequently it was concluded that $R h t 1$ is carried by $4 \mathrm{~A}$. No recombination was found between Gai 1 and Gai 3, the gibberellin insensitivity gene in " Tom Thumb "type dwarf wheats, indicating that these genes are either alternative alleles at the same locus or are closely linked.
\end{abstract}

\section{INTRODUCTION}

Norin 10-Brevor 14 (NB 14) was derived from a cross between the Japanese dwarf and an American variety. This line is the major source of the semidwarfing character common to many present-day commercial wheat varieties. NB14 carries two alleles that confer "insensitivity" of aerial plant parts to application of the phytohormone, gibberellic acid (GA). One of these alleles, Gai 2, has been shown to be located on chromosome 4D by Gale et al. $(1975 b)$. They also showed that the segregation of Gai 2/gai 2 was closely associated with variation in height in a GA-insensitive (GAI) semi-dwarf $\times$ GA-responsive tall wheat cross.

The positive association between GAI and height reduction has been shown for both Gai 1 with Rht 1 and Gai 2 with Rht 2 in crosses involving Norin 10 derivative semi-dwarfs (Gale and Marshall, 1973; Hu, 1974) and for Gai 3 with Rht 3, the genes controlling GAI and dwarfism in "Tom Thumb"-type dwarf wheats (Gale et al., 1975a; Fick and Qualset, 1975). Whether the nature of this association is pleiotropic, i.e. the Gai and Rht genes are, in fact, the same, or due to linked loci, as suggested by Konzak et al. (1973), it is clear that the chromosomal locations of Gai 1, Gai 2 and Gai 3 are the same as those of Rht 1, Rht 2 and Rht 3. The location of Gai 3 (Gale et al., 1975a) and Rht 3 (Morris et al., 1972) has already been ascertained as chromosome 4A. Only Gail/Rht 1 remains unmapped.

So far only $R h t 2$ has been exploited in British semi-dwarfs such as Maris Fundin and its successors. There is some evidence to suggest that Rht 1 may have some agronomic advantages and be a better genetic base for semi-dwarfs than Rht 2, which produces the shorter straw (Allan, 1970). Knowledge of the location of Gai 1, and thus Rht 1, will assist in its future incorporation into adapted lines and in assessing the agronomic worth of such derivatives. This would allow the gene(s) to be manipulated by standard aneuploid techniques (Law and Worland, 1972) and be recognised and followed by its qualitative GAI phenotype rather than the quantitative effect on height. 
This paper describes experiments that have led to the determination of the chromosomal location of Gai 1.

\section{Genotypes and methods}

The varieties used include SDl, a Norin 10 derivative kindly supplied by Dr R. E. Allen, Washington State University; Norin 10-Brevor 14 (NB14) a short derivative from the cross Norin $10 \times$ Brevor extracted by Dr O. E. Vogel; Hobbit, a semi-dwarf variety bred by Dr F. G. H. Lupton and known to carry Rht 2 and Gai 2 (Gale et al., 1975b); Olsen, an extreme dwarf that is known to carry both Gai 1 and Gai 2 (Gale, unpublished) as well as another unidentified height reducing gene (Fick and Qualset, 1973) and Tom Thumb and Minister Dwarf, dwarf lines carrying Rht 3 and Gai 3 on chromosome 4A. The monosomic series of Bersee and Cappelle-Desprez (Law and Worland, 1972) were used for $F_{2}$ monosomic analysis (Sears, 1953) of the GAI genes in SDl and Olsen respectively.

GA-response tests were carried out under controlled environments as described in Gale et al. (1975b).

\section{RESUlts}

The results of $\mathrm{F}_{2}$ GA-response analyses from crosses of SDl with three testers are shown in table 1 . These confirm that SDl carries only Gai 1.

TABLE 1

$F_{2} G A$-response analyses to determine the Gai allele carried by SD1. Known parental genotypes, Chinese Spring-gai 1 gai 2; NB14-Gai 1 Gai 2; Hobbit-gai 1 Gai 2. I, GA insensitive and $R$, GA-responsive

\begin{tabular}{lccc}
\multicolumn{1}{c}{ Cross } & I:R & Ratio & Inference concerning SDI \\
SDl $\times$ Chinese Spring & $72: 28$ & $3: 1$ & Carries a single Gai gene . . . which is \\
$\mathrm{SDl} \times$ NB14 & $100: 0$ & - & either Gai I or Gai $2 \ldots$ and is different \\
SDl $\times$ Hobbit & $95: 5$ & $15: 1$ & from Gai $2 \ldots$ therefore SDl carries Gai 1
\end{tabular}

Eighteen of the possible 21 monosomics of Bersee were crossed with SDl using the aneuploid as the female parent. Duplicate $\mathrm{F}_{1}$ monosomic $(2 n-\mathrm{l})$ hybrids, each carrying a hemizygous chromosome from SDl, were grown and grain collected to produce $F_{2}$ plants. This grain was germinated and, after the removal of root tips for subsequent cytological examination, transferred to vermiculite for a GA response test.

The results for the monosomic families combined over duplicates and for the disomic controls are shown in table 2. The critical chromosome, that carrying Gai 1, is expected to deviate from the ratio 3 insensitive: 1 responsive found in the control by an increase in the insensitive fraction. Two families, $4 \mathrm{~A}$ and $4 \mathrm{~B}$, deviated in this way. For all families, the root tips of a sample of responsive and insensitive seedlings were checked for chromosome number, while for $4 \mathrm{~A}$ and $4 \mathrm{~B}$ the families were checked in greater detail. In all families except Bersee $4 \mathrm{~A} / \mathrm{SDl}$ the GA response was independent of chromosome number.

A further sample of $F_{2}$ seedlings from Bersee $4 \mathrm{~A} / \mathrm{SDl}$ was grown and the results, combined with those of the first sample, are shown in fig. 1 , where the GA response, shown as the length of the second leaf-internode after exposure 
TABLE 2

$G A$ response of $F_{2}$ monosomic families of Bersee $\times S D l$. I, GA insensitive (Gai 1.) and $R, G A$ responsive (gai 1 gai 1 )

\begin{tabular}{|c|c|c|c|c|c|c|}
\hline \multirow[b]{3}{*}{ Group } & \multicolumn{6}{|c|}{ Genome } \\
\hline & \multicolumn{2}{|c|}{ A } & \multicolumn{2}{|c|}{ B } & \multicolumn{2}{|c|}{$\mathrm{D}$} \\
\hline & I & $\mathrm{R}$ & I & $\mathbf{R}$ & I & $\mathrm{R}$ \\
\hline 1 & 25 & 10 & 24 & 9 & 33 & 7 \\
\hline 2 & 二 & - & 18 & 3 & 11 & 4 \\
\hline 3 & 25 & 10 & 9 & 3 & 28 & 10 \\
\hline 4 & 37 & $1 * * *$ & 34 & $6 *$ & 32 & 8 \\
\hline 5 & 27 & 11 & 12 & 4 & 30 & 7 \\
\hline 6 & 29 & 11 & 29 & 9 & 27 & 11 \\
\hline 7 & - & - & 30 & 6 & - & - \\
\hline Euploid control & 36 & 11 & & & & \\
\hline
\end{tabular}

$\chi^{2}$ deviation from $3: 1$ ratio.

$* \mathrm{P}=0 \cdot 05 ; * * * \mathrm{P}<0 \cdot 001$.
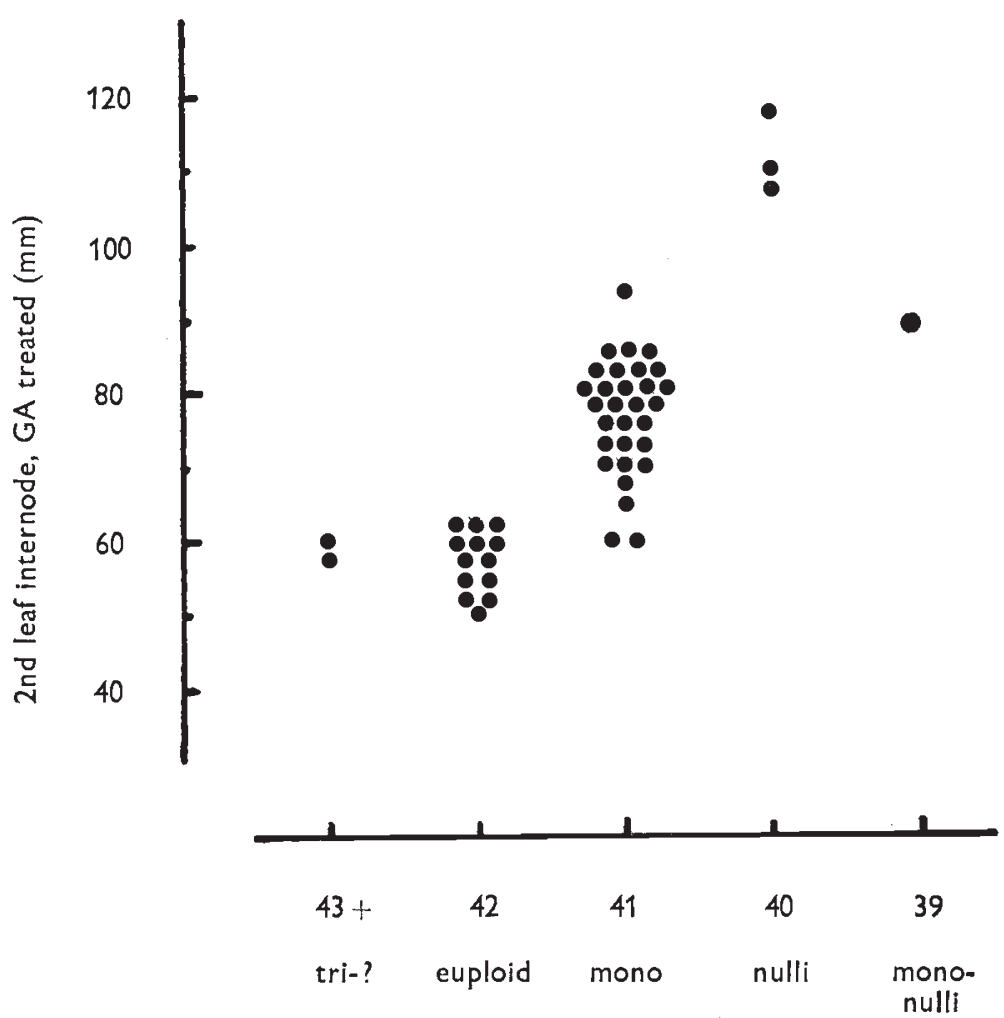

FIG. 1.-GA-response and chromosome number in Bersee 4A/SDl $\mathrm{F}_{2}$ monosomic seedlings. 
to GA, is plotted against chromosome number. Clearly the extension of this part of the seedling is associated with the different doses of chromosome $4 \mathrm{~A}$ from SDl in 42, 41 and 40 chromosome seedlings.

This result was checked by a similar experiment involving $\mathrm{F}_{2}$ seedlings from Cappelle-Desprez 4A/Olsen. Since Olsen carries Gai 1 and Gai 2 the expected $\mathrm{F}_{2}$ euploid and non-critical monosomic segregation will be 15 insensitives: 1 responsive. For the critical monosomic $\mathrm{F}_{2}$ all the progeny should be insensitive except those nullisomics homozygous for gai 2 . In the $4 \mathrm{~A}$ monosomic family, 80 seedlings were tested and only two of these were responsive. Although this does not differ from the expected disomic segregation $\left(\chi_{(1)}^{2}=1.9, \mathrm{NS}\right)$ the responders were found to have chromosome numbers of 40 and 39 . The 39 chromosome plant may reasonably be assumed to have been a $4 \mathrm{~A}$ nullisomic which was monosomic for another, non-critical chromosome. This result confirms chromosome $4 \mathrm{~A}$ as the location of Gai 1.

Chromosome $4 \mathrm{~A}$ is also the carrier of Gai 3, the strong insensitivity gene present in Tom Thumb dwarfs (Gale et al., 1975a; Gale and Marshall, 1975). Thus the observation that the same chromosome carries Gai 1 necessitated a close look at the relationship of these two genes in segregating families. Grain from bagged $F_{1}$ spikes, in which the possibility of outcrossing was absent, was available from hybrids of either Tom Thumb or Minister Dwarf (Gai 3) with NB14 or Olsen (Gai 1 Gai 2) i.e. TT $\times$ Olsen, MD $\times$ Olsen, $\mathrm{TT} \times \mathrm{NB14}$ and $\mathrm{MD} \times \mathrm{NB} 14$. Assuming independent assortment these $\mathrm{F}_{2}$ 's would be expected to segregate 63 insensitive: 1 responsive in a GA response test. Among 1600 such seedlings no full responders was observed indicating that Gai 1 and Gai 3 are either alternative alleles at the same locus or closely linked.

Of course, in a three-gene duplicate system such as this, the $F_{2}$ is a very inefficient estimator of linkage. Although the estimate of linkage from this experiment is zero, it may be shown that a recombination value as high as 17.3 per cent will give a similar result with a probability of 5 per cent. Clearly then, the $\mathrm{F}_{2}$ results establish linkage between Gai 1 and Gai 3 on chromosome $4 \mathrm{~A}$ and suggest, but by no means prove, that they may be alternative alleles at the same locus.

In order to reach a more definite conclusion 20 grains from the tallest field grown $\mathrm{F}_{2}$ 's from the same families were progeny tested. The tallest were chosen since these would be the most likely to carry fewest Gai/Rht alleles. Among the 42 families sampled from a total of 560 , four were found to contain a single partially responsive seedling as might be expected of the Gai 1 gai 1 heterozygote. No fully responsive plants were observed. It seems likely that, in the absence of any "all-responsive" families or any segregating $3 \mathrm{I}: 1 \mathrm{R}$ or $15 \mathrm{I}: 1 \mathrm{R}$ that the partial responders were the result of outcrossing. In this case the zero estimate of recombination has a 5 per cent confidence limit of 0.7 per cent which considerably reinforces the possibility that Gai 1 and Gai 3 are alleles.

\section{Discussion and conglusions}

The exact nature of the relationship between gibberellin insensitivity and height reduction is of practical importance to the bread wheat, macaroni wheat and triticale breeders who are using the Norin 10 and Tom Thumb 
sources of dwarfism. Clearly a linkage relationship whereby the Gai and Rht genes can be manipulated independently is more attractive. Thus, as the relative agronomic advantages and disadvantages of either phenotype produced by any of the alleles become known, the genes may be exploited more fully. However if $R h t$ semi-dwarfs are short because of their lack of ability to utilise endogenous gibberellins, i.e. the Rht and Gai phenotypes represent pleiotropic expression of a mutation at a single locus, then the breeder's possibilities are restricted to accepting GA-insensitivity and short straw as a package.

The main problem involved in ascertaining the genetic relationship between the pairs of $G a i$ and $R h t$ genes is that the difference between the Gai and gai phenotypes is qualitative while the difference between the $R h t$ and $r h t$ phenotypes is quantitative and is usually considerably confounded by the other genetic differences affecting the plant height phenotype in segregating plants or families. Thus in a segregating family, although plant height is clearly strongly associated with Gai genotype, it is not always clear whether the variation in plant height within plants of known Gai genotype is due to segregation of the Gai and Rht loci, to other modifying genes effecting height in the presence of a single Rht genotype or even to environmental effects on plant height.

The clearest situation should be in the segregating progeny from tall $x$ "Tom Thumb" type crosses since the height reduction effects of Rht 3 are so large as to be considered almost qualitative. In more than $1000 \mathrm{~F}_{2}$ individuals we have observed no tall Gai 3 homozygotes or dwarf gai 3 homozygotes indicating either extremely tight linkage between $R h t 3$ and Gai 3 or more probably that both phenotypes are controlled by the same gene. However the observation by $\mathrm{Hu}$ (loc. cit.) that two $\mathrm{F}_{3}$ families from a similar cross, that were considered to be homozygous for height, segregated for GA-insensitivity in a seedling test indicates that recombination may indeed be possible.

Other circumstantial evidence is available for both hypotheses. In favour of pleiotropy, the relative potencies of the Gai alleles in terms of GA-insensitivity exactly coincides with the relative height reducing effects of their respective Rht alleles-in potency Gai 3> Gai $2>$ Gai 1 and in degree of dwarfness produced Rht $3>$ Rht $2>$ Rht 1 . Also, all of the semi-dwarf lines produced in breeding programmes at this Institute and those that we have tested from the CYMMIT programme in Mexico display the GA-insensitive reaction. This could, however, indicate agronomic advantages associated with the Gai alleles rather than the Gai and Rht genes being the same. On the other hand, given the observation that Gai 1 and Gai 3 are either at the same locus on $4 \mathrm{~A}$ or, at most, less than one map unit apart, the several reports of independence between the "Tom Thumb" type of dwarfish and the two Norin 10 dwarfing genes (e.g. Piech, 1968; Chaudhry, 1973; Fick and Qualset, 1973) would appear to indicate that $R h t 1$ and $R h t 3$ are separate and therefore confirm that at least one may be separated from its Gai allele.

This conclusion is open to criticism now that the chromosomal locations of all three $R h t$ genes are known. The basis of the genetic independence has, in each case, been based upon the observation of transgressive segregation in an $\mathrm{F}_{2}$, i.e. plants with longer straw than that of the taller parent have been recorded. Since Norin 10 and Norin 10-Brevor 14 carry two additive $R h t$ genes and Tom Thumb carries only a single strong Rht gene, transgressive segregation would be expected whether $R h t 1$ and $R h t 3$ were independent i.e. 
Rh 1 Rht 2 rht $3 \times$ rht 1 rht 2 Rht 3 or allelic i.e. Rht 1 Rht $2 \times$ Rht 3 rht 2 . The difference would lie in that the first possibility would yield taller segregants, i.e. $\frac{1}{64}$ rht 1 rht 2 rht 3, than the second, i.e. $\frac{1}{16}$ Rht 1 rht 2 .

The data shown in fig. 2 represent the pooled $F_{2}$ distributions of two types of cross, in which Rht 1 and Rht 2 segregate with Rht 3 (type 1) or without $R h t 3$ (type 2). If Rht 1 and $R h t 3$ were independent, plants as tall as the tallest from type 2 would be expected in type 1 but with a quarter of

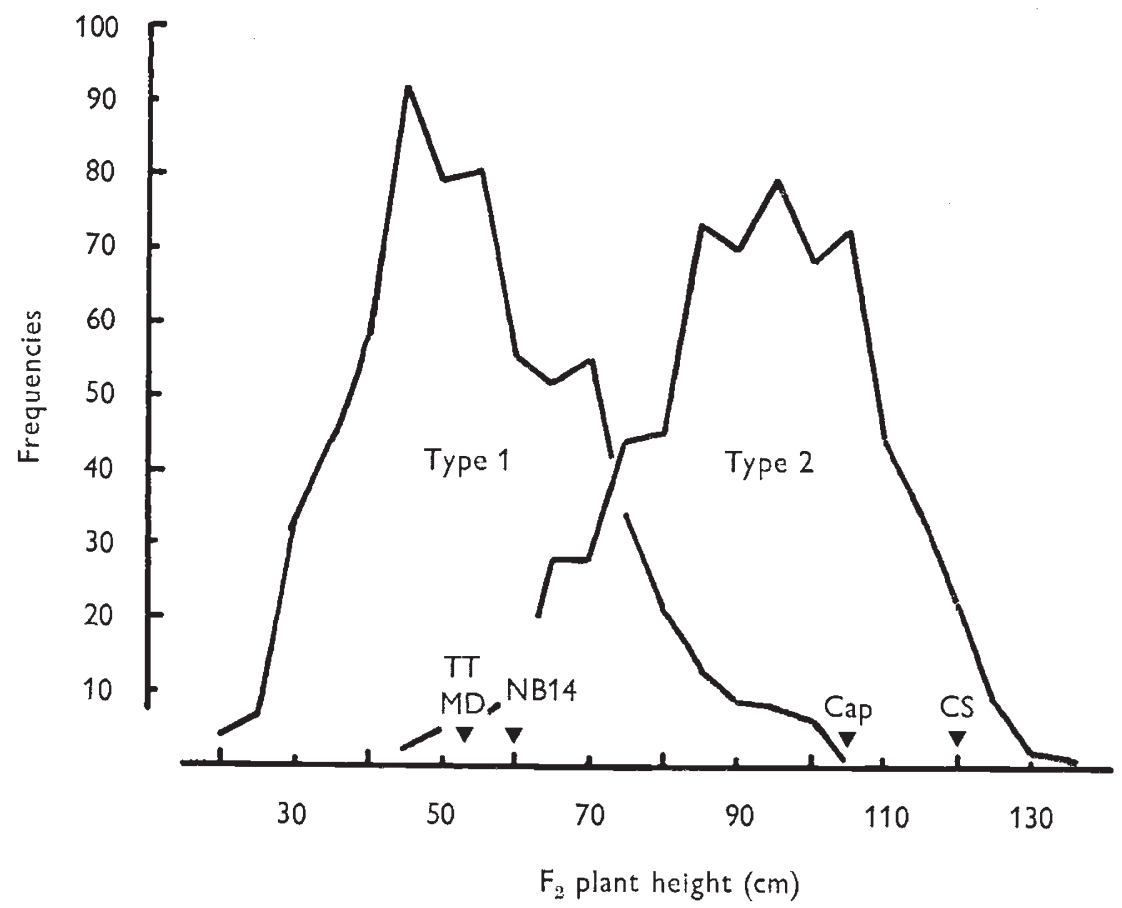

FIG. 2.- $\mathrm{F}_{2}$ plant height distributions-comparison of combined data for $R$ ht 1 Rht $2 \times$ Rht 3 (type 1) and rht $3 \times R h t 1$ Rht 2 (type 2). Parents: Rht 1 Rht 2 Norin 10-Brevor 14, Rht 3 Tom Thumb and Minister Dwarf: rht Cappelle-Desprez and Chinese Spring.

the frequency. No such plants are observed even though the number of individuals is in excess of 650 . Of course, another reason for the apparent lack of talls in the type 1 crosses could be the presence of dispersed genes for tallness present only in type 2 . This, while not impossible, seems unlikely since NB14 (Rht 1 Rht 2) is common to all crosses and the tall parents in type 2, Chinese Spring and Cappelle-Desprez are only of standard height. Also, similar $F_{2}$ height frequency distributions were obtained by Fick (1971) from type 1 and 2 crosses involving different parents indicating that the lack of tall plants in type 1 is more likely to be due to the spatial arrangement of the $R h t$ alleles than to the presence of height promoting gene combinations only in type 2.

The type 1 crosses are those from which the $F_{3}$ progeny tests discussed earlier were taken, in which no GA-responsive plants or families were found. Taken together these results are most compatible with the hypothesis that the Gai and Rht alleles are the same, at least for Gai/Rht 1 and Gai/Rht 3. 
These experiments conclude the chromosomal mapping of the known Gai alleles in hexaploid wheat. It was, perhaps, not surprising that the two loci definitely established are carried within a single homoeologous group. The genes are qualitatively similar, if quantitatively dissimilar, in their action (Gale and Marshall, 1975) and consequently it is probable that they form part of a homoeologous series across the group 4. Thus there is wide scope for the discovery of other alleles either on the apparently vacant chromosome $4 \mathrm{~B}$ or as alternative alleles at the other loci. Considering the success following the exploitation of Gai/Rht 1 and Gai/Rht 2 in commercial semi-dwarfs and the potential use of Gai/Rht 3 for the production of low $\alpha$-amylase quality wheats, a search for other similar genes among collections or in mutation experiments may be well worthwhile.

Acknowledgments.-We would like to thank Mrs J. M. Chambers and Mr A. J. Worland for their technical assistance and $\mathrm{Mr} \mathrm{B}$. Westcott for advice on statistical matters.

\section{REFERENGES}

ALLAN, R. E. 1970. Differentiating between Norin 10/Brevor 14 semi-dwarfing genes in a common genetic background. Seiken Ziho, 22, 83-90.

CHAUDHRY, A. s. 1973. A genetic and cytogenetic study of height in wheat. Ph.D. Thesis, Cambridge University.

FICK, G. N. 1971. Genetic control of plant height and coleoptile length and association with gibberellic acid response and $\alpha$-amylase activity in short strawed wheats. Ph.D. Thesis, University of California, Davis.

FICK, G. N., AND QUALSET, C. o. 1973. Genes for dwarfness in wheat Triticum aestivum. Genetics, 75, 531-539.

FICK, G. N., AND QUALSET, C. o. 1975. Genetic control of endosperm amylase activity and gibberellic acid responses in standard-height and short strawed wheats. Proc. natn. Acad. Sci., U.S.A., 72, 892-895.

Gale, M. D., AND marshall, G. A. 1973. Dwarf wheats and gibberellins. Proc. 4th Int. Wheat Genetics Symposium, 513-519.

GALE, M. D., AND MARShall, G. A. 1975. The nature and genetic control of gibberellin insensitivity in dwarf wheat grain. Heredity, 35, 55-65.

GALE, M. D., LAW, C. N., MARshall, G. A., AND WORLAND, A. J. 1975a. The genetic control of gibberellic acid insensitivity and coleoptile length in a "dwarf" wheat. Heredity, 34, 393-399.

GALE, M. D., LAw, C. N., AND WorLAND, A. J. 1975b. The chromosomal location of a major dwarfing gene from Norin 10 in new British semi-dwarf wheats. Heredity, 35, 417-421.

HU, м. L. 1974. Genetic analyses of semi-dwarfing and insensitivity to gibberellin, $\mathrm{GA}_{3}$, in hexaploid wheat. Ph.D. Thesis, Washington State University.

KONZAK, C. F., SADAM, MIR., AND DONALDSON, E. 1973. Inheritance and linkage in durum wheats of semi-dwarfing genes with low response to gibberellin $\mathrm{A}_{3}$. Proc. Symp. Genetics and Breeding of Drum Wheat, Bari 1973, 29-40.

LAW, C. N., AND WORLAND, A. J. 1972. Aneuploidy in wheat and its uses in genetic analysis. Plant Breeding Institute Annual Report, 1972, 26-65.

MORRIs, R., SCHMIDT, J. w., AND JOHNSON, v. A. 1972. Chromosomal location of a dwarfing gene in Tom Thumb wheat derivatives by monosomic analysis. Crop Sci., 7, 275-276.

PIECH, J. 1968. Monosomic and conventional genetic analyses of semi-dwarfism and grassclump dwarfism in common wheat. Euphytica, suppl. 1, 153-170.

SEARS, E. R. 1953. Nullisomic analysis in common wheat. Am. Nat., 87, 245-252. 